\title{
Analyzing Social Marketing Characteristics of Indian Companies
}

\author{
Jinyoung Shin ${ }^{1}$, Jaesin $\mathrm{Oh}^{2}$ and Dae-Yul Jeong ${ }^{3 *}$ \\ ${ }^{1}$ Research Professor, Institute of Indian Studies, Hankuk University of Foreign \\ Studies, Seoul, Korea \\ ${ }^{2}$ Professor, Dept. of Industrial Management, Research Fellow of BERI,Gyeongsang \\ National University, Jinju, Korea \\ ${ }^{3}$ Corresponding Author, Professor, Dept. of Management Information Systems, \\ Research Fellow of BERI, Gyeongsang National University, Jinju, Korea \\ ${ }^{1}$ iddialover@gmail.com, ${ }^{2}$ jsoh@gnu.ac.kr, ${ }^{3}$ dyjeong@gnu.ac.kr
}

\begin{abstract}
This study analyzed the social marketing characteristics of Indian companies. The top 100 Indian companies in terms of market caps were selected, and their latest social marketing activities in 2017-2019 were researched. This study focused on the social marketing topics of the companies. Empirical analysis was conducted to compare the difference among the company group. The most common social marketing topics are health, followed by environment and education. As a result of the difference analysis between groups, there was a statistically significant difference in social marketing theme according to the nationality of the company. On the other hand, there was no statistical difference according to the ownership type of the company and the industry. However, although some tests are not statistically significant, the difference analysis provided in-depth implications for the social marketing characteristics of Indian companies.
\end{abstract}

Keywords: Indian companies, Social marketing, Social marketing topics, Corporate social responsibility, CSR

\section{Introduction}

The purpose of this study is to analyze the current status and characteristics of social marketing in India. There have been some researches on Corporate Social Responsibility (CSR) activity of Indian companies in the industry and academic society [1]. However, researches on social marketing activities has been very limited and most of the researches focused on specific fields such as medical and health care [2]. Therefore, it is difficult to understand the social marketing status of Indian companies by previous researches. To address these limitations, this study investigates in social marketing practices of the top 100 companies in India. Specifically, their social marketing characteristics were analyzed, focusing on target audiences and marketing topics. The results of this study will not only provide insight into India market, a representative emerging market, but also give some implications to the companies who have already entered or are preparing to get into India for planning social marketing program. It will also provide a new perspective on social marketing to the other countries where social marketing is not active.

Article history:

Received (December 14, 2019), Review Result (January 21, 2020), Accepted (March 6, 2020) 


\section{Social marketing review in India}

Social marketing and CSR are hard to distinguish, and some scholars see social marketing as part of CSR activities. Belz \& Ken suggest that social marketing and CSR are both similar in that they aim to bring benefits to various stakeholders [1]. According to them, the difference is that social marketing is concerned about customers and their long-term interests, but CSR is more focused on corporate stakeholders. In recent years, the scope of CSR activities has gradually expanded, and private companies have increased their interest in social marketing [3][4]. Therefore, the boundary between CSR and social marketing is expected to be blurred. Lefebvre defined that "social marketing is an application of marketing techniques to social issues and problems, providing an innovative and developmental framework for solving social problems" [5]. Paek defines "social marketing is a process of developing, implementing, and evaluating programs to induce the voluntary change of individual behavior for the public good by utilizing the technology of commercial marketing" [6].

The history of social marketing in India began with family planning, which started in 1964 at the Indian Institute of Management, Calcutta [7]. Social marketing was used in family planning to control fertility rates and encouraging the use of condoms. Later, social marketing was used mainly by India's Ministry of Health and Welfare. Since the 1990s, the Indian government has set up a Social Marketing Organization, and it started campaigns for family planning. In the 2000s, Indian private companies became interested in social marketing and developed various social marketing programs. Since CSR activities are legally regulated in India, companies are carrying out various CSR activities in long term perspective. On the other hand, some companies fulfilled social marketing relatively in a short-term perspective. It is pointed out that myopic social marketing activities are not systematic [8].

The history of social marketing in India began with family planning, which started in 1964 at the Indian Institute of Management, Calcutta [7]. Social marketing was used in family planning to control fertility rates and encouraging the use of condoms. Later, social marketing was used mainly by India's Ministry of Health and Welfare. Since the 1990s, the Indian government has set up a Social Marketing Organization, and it started campaigns for family planning. In the 2000s, Indian private companies became interested in social marketing and developed various social marketing programs. Since CSR activities are legally regulated in India, companies are carrying out various CSR activities in long term perspective. On the other hand, some companies fulfilled social marketing relatively in a short-term perspective. It is pointed out that myopic social marketing activities are not systematic [8].

The social marketing research of India is as follows. First, there are some studies to find out social marketing origin from Indian traditional context that encourages social good. Joshi (2018) studied the social marketing case from traditional Vedic philosophy. The case analyzes the origins of social marketing in India that lead to social change and social good [2]. On the other hand, Wasan \& Tripathi focuses on the 4P (Pubic, Partnership, Policy, Purse String) strategy emphasized in previous social marketing research. They analyzed the socio-cultural elements of India and stressed the need to take this $4 \mathrm{P}$ into account in the social marketing program development [8]. Until now, most of India's research on social marketing has been conducted in a limited area, focusing on specific organizations such as NGOs and health organizations [8][9][10][11]. Singh et al. conducted a study analyzing social marketing practices of social enterprises in India [12].

It is difficult to identify general Indian companies' social marketing characteristics by previous studies. This is because the social marketing case studies based on some traditional Indian values were only to analyze the socio-cultural elements of India to consider in social 
marketing planning. In addition, case studies on specific companies such as health-care organizations or social enterprises, have limitations in understanding the social marketing status of Indian profit companies and providing implications. Moreover, interest in social marketing of India is on the rise, nevertheless, the lack of research on social marketing of Indian private companies is not enough to provide sufficient information for companies who are interest to entering India market

The representative social marketing cases of the top-level companies in each sector are as follows. Tata Group, a leading business group in India, was established in 1868 and has expanded its business area and now operates in over 100 business areas. Tata Group is the first company to launch the eight-hour labor system (1912), paid leave (1920), maternity leave (1928), performance incentive (1934), and retirement pay system (1937). So, the group led to the welfare of employees in India. The most notable social marketing case promoted by the Tata Group was the improvement program of the "women's rights" by Tata Suns (holding company) and Tata Tea (food and beverage).

Currently, Reliance Industries Ltd., India's No.1 conglomerate company in sales volume, has conducted social marketing for the whole nation. In 2015, Reliance conducted a social marketing program that boosted patriotism with a catchphrase called 'Salute Selfie'. In 2019, the Reliance Group is conducting social marketing under the catch-phrase, "Clean Ganga (clean river)".

Godreji Group is one of India's largest conglomerates, business on the household goods industry, including soap and cooking oil. Godreji was carrying out comprehensive and sustainable social marketing with the catchphrase "Good \& Green", and recently launched campaigns to inform the importance of potential of renewable energy and sustainable development for the people of underprivileged region.

Asia Paint established in Mumbai in 1942 and produces and sells paints, coatings, household products, and bathroom products. The representative social marketing program of Asian Paint is 'Safar', which promotes the importance of hygiene and prevention, as well as improving hygiene concepts and awareness of AIDS disease for trucks drivers and others.

Hindustan Unilever has been conducting social marketing focused on hygiene and health for children. In 2013, the company launched a campaign with a catchphrase, "Help a Child reach 5 ". The social marketing of this company aims to reduce infant mortality in India where 1.3 million children under five die. In 2018-19, the social marketing with the catchphrase, "Playing Billion," continued to reduce child mortality rates through daily hygiene activities.

Power Grid Corporation of India (PSU) conducts social marketing in line with the government's anti-corruption campaign. Specifically, the company promoted anti-corruption campaign marathon with employees and their families, to remind them of their awareness of honesty and integrity, and to raise awareness of an anti-corruption with the catchphrase "Awareness Gram Sabhas".

\section{Research method}

\subsection{Research hypotheses}

The topic of social marketing cannot be separated from the nature of the company and the social marketing target audience. In the case described earlier, the marketing topic of 'Power Grid Corporation of India (PSU)' is based on integrity, honesty, etc., which is emphasized by the Indian government [13]. On the other hand, private firms focus on improving health, 
hygiene, and individual conception, and so on which are more closely related to the daily life of the public rather than government-related topics.

In the case of Reliance Industries Ltd., industrial goods company, the topic of social marketing is patriotism, which is a general interest of whole people in India. On the other hand, Tata Tea is deciding on a social marketing topic that women might be interested in, such as sharing household chores. In the case study, the industrial goods sector is relatively less focused on specific potential consumers than consumer goods, therefore the topic of social marketing of industrial goods sector are general theme.

Lastly, the subject of social marketing is expected to be different depending on the company's top decision makers or the company's policies. In the case of Tata Steel, an Indian company, the social marketing topic was focused on the environment of garbage and energy, while Hindustan Unilever, a foreign company, emphasized the personal hygiene of children. In other words, representatives of foreign companies may have different perceptions of social issues from Indian companies and the topic of social marketing is expected to depend on a decision of nationality of the company. Thus, the following hypothesis is derived.

Hypothesis 1: There will be differences in the topic of social marketing depending on the type of ownership of the company (private vs. public).

Hypothesis 2: There will be differences in the topic of social marketing depending on industry fields (consumer vs. industrial).

Hypothesis 3: There will be differences in the topic of social marketing depending on the nationality of the company (India vs. foreign).

\subsection{Data collection and sample}

The top 100 companies list in India's BSE market cap on October 1, 2019 was collected [14]. In the list of top companies, each company's social marketing case was selected according to the definition of social marketing. Specifically, cases satisfying all three of the following conditions were selected from social marketing or CSR activities of a company. (1) for the purpose of the public interest, (2) a program that induces the voluntary change of individual behavior, and (3) the amount of investment and actually program cost for execution. The social marketing cases were selected with the most recent one, cases in 2019. If there were no social marketing cases in 2019, then we collected social marketing cases within the last three years after 2017. [Table 1] shows the characteristics of sample.

Table 1. The characteristics of sample

\begin{tabular}{|c|c|c|c|}
\hline \multirow{2}{*}{ Category } & $\mathrm{N}$ & Total \\
\hline \multirow{2}{*}{ Ownership } & Private & 75 & \multirow{2}{*}{100} \\
\cline { 2 - 3 } & Public & 25 & \multirow{2}{*}{100} \\
\hline \multirow{2}{*}{ Industry fields } & Consumer goods & 46 & \multirow{2}{*}{100} \\
\cline { 2 - 3 } & Industrial goods & 54 & \\
\cline { 2 - 3 } Nationality & India & 75 & 25 \\
\cline { 2 - 3 } & Foreign & & \\
\hline
\end{tabular}

\subsection{Data analysis method}

The statistical program SPSS 24.0 was used for analysis. First, descriptive statistics analysis was used to identify the current status of research firms and target audiences and marketing 
topics of social marketing. Target audience of Indian companies were children, students, adolescents, women, the general public, local people, underprivileged people, truck drivers, and tribal people. Pearson chi-square test was conducted to analyze whether there was a difference in social marketing target audiences and marketing topics by groups. For the chisquare test, the number of cases was set to over 25 so that the expected frequency of each cell was 5 or more. The Cramer's V-analysis was used to identify the strength of the coefficient and to test the hypotheses.

\section{Data analysis and results}

The results of the topic analysis by company type are as follows. By type of ownership, private firms had the highest social marketing topic for health, while PSUs had the "Other" such as combating corruption and giving way to ambulances. According to the analysis of the marketing topic by ownership type, $53.3 \%$ of private sectors and $36 \%$ of public corporations were on health. In the case of PSUs, $44 \%$ of 'others' are high in social marketing topics, while $12 \%$ of 'others' in the private sector. The result of the chi-square test on marketing topic by ownership, the Pearson chi-square value was 14.073 with probability value 0.007 ( $\mathrm{P}<0.01)$, so it shows statistically significant. The Cramer's V-value is 0.408 , which suggests that there is medium correlation between the topics of social marketing by the type of ownership.

By industry, both the consumer and industrial goods had the highest health topics, and 'Others', such as disability awareness and road safety, is also high. On the other hand, the environmental topic was $18.5 \%$ for industrial goods companies, while $8.7 \%$ for consumer goods companies. The chi-square test on marketing topics by industry fields showed that the Pearson chi-square value was 2.712 with probability value $0.607(\mathrm{P}>0.05)$, which was not statistically significant.

By nationality of company, health was the highest topic both in Indian and foreign companies, but there was a difference in the second ranking. 'Environment' was the second in Indian companies, while 'other (road safety and citizenship)' was the second in foreign companies. The chi-square test on marketing topics by nationality showed that the Pearson chisquare value was 6.090 with probability value $0.193(\mathrm{P}>0.05)$, which was not statistically significant.

Table 2. Homogeneity test of marketing topics according to characteristics of the companies

\begin{tabular}{|c|c|c|c|c|c|c|c|c|}
\hline \multirow{2}{*}{\multicolumn{2}{|c|}{ Categories }} & \multicolumn{5}{|c|}{ Marketing Topic N (\%) } & \multirow{2}{*}{$\chi^{2}(\mathrm{p})$} & \multirow{2}{*}{$\begin{array}{c}\text { Cramer'sV } \\
\text { (p) }\end{array}$} \\
\hline & & Health & $\mathrm{Edu} / \mathrm{Tec}$ & Environ. & Dream/E & Others & & \\
\hline \multirow{2}{*}{ Ownership } & Private & $40(53.3)$ & $7(9.3)$ & $12(16)$ & $7(9.3)$ & $9(12)$ & \multirow{2}{*}{$\begin{array}{c}14.073 \\
(0.007)^{* *}\end{array}$} & \multirow{2}{*}{$\begin{array}{c}0.375 \\
(0.007)^{* *}\end{array}$} \\
\hline & Public & $9(36)$ & $3(12)$ & $2(8)$ & 0 & $11(44)$ & & \\
\hline \multirow{2}{*}{$\begin{array}{l}\text { Industry } \\
\text { fields }\end{array}$} & $\begin{array}{c}\text { Consumer } \\
\text { goods }\end{array}$ & $24(52.2)$ & $6(13)$ & $4(8.7)$ & $3(6.5)$ & $9(19.6)$ & \multirow{2}{*}{$\begin{array}{c}2.712 \\
(0.607)\end{array}$} & \multirow{2}{*}{$\begin{array}{c}0.165 \\
(0.607)\end{array}$} \\
\hline & $\begin{array}{l}\text { Industrial } \\
\text { goods }\end{array}$ & $25(46.3)$ & $4(7.4)$ & $10(18.5)$ & $4(7.4)$ & $11(20.4)$ & & \\
\hline \multirow{2}{*}{ Nationality } & India & $36(48)$ & $9(12)$ & $13(17.3)$ & $5(6.7)$ & $12(16)$ & \multirow{2}{*}{$\begin{array}{c}6.090 \\
(0.193)\end{array}$} & \multirow{2}{*}{$\begin{array}{c}0.247 \\
(0.193)\end{array}$} \\
\hline & Foreign & $13(52)$ & $1(4)$ & $1(4)$ & $2(8)$ & $8(32)$ & & \\
\hline
\end{tabular}




\section{Conclusion and discussion}

Social marketing is aimed at the behavior or perception change of marketing audiences. It is the most needed activity in developing countries with rapid social change, lack of wellequipped social infrastructure, and less opportunity to develop basic citizenship. The purpose of this study is to establish the direction of social marketing of companies in developing countries by analyzing the characteristics of social marketing in India. For this, the survey was conducted on the homepages and articles of the top-level 100 companies in India, and that was used to analyze characteristics of social marketing focusing on marketing topics.

According to the result, the target audience of social marketing in India was $42 \%$ of all citizens, followed by socially disadvantaged people such as children and women. The major of marketing topics was health, and the topics of environment, education/technology, dream/empowerment were also high. As a result of hypothesis testing whether there are differences in social marketing topic by ownership type, industrial field, and nationality (India / foreign). Indian companies are interested in education, technology, and environment, while foreign companies are approaching various topics such as road safety and citizenship.

The trends of social marketing of Indian companies are as follows. First, it emphasizes health for the whole nation citizen, which is not much different from social marketing trends in other countries. This seems to indicate that India's society needs an emphasis on health and medical environment. Second, it is noteworthy that foreign companies have a high proportion of children as target audiences. This is because the future growth of the Indian market is high. Third, social marketing is less organized than CSR activities in India, however it is worth noting that there is a tendency that social marketing is progressing such as promotion of social marketing series around 2015 or various ways based on the same theme. Therefore, companies entering India will need to establish differentiated social marketing rather than simple and corporate image marketing to build that pursues 'social good', Moreover, it is necessary to consider specialized social marketing program for potential customers.

This study complements the lack of systematic research and analysis on the social marketing topics and target audiences of private companies. In addition, in order to investigate the current status of social marketing of Indian companies, the top-level 100 companies' cases have been surveyed, analyzed and verified. In this regard, the study is meaningful. However, this study only included large companies and public enterprises in India, and there is a lack of research on SMEs that are doing well in social marketing. If a broader study is conducted in the future, it will be possible to characterize social marketing of various Indian companies. In addition, if marketing topics is analyzed in more detail, more meaningful results will be found.

\section{Acknowledgements}

This work was supported by the National Research Foundation of Korea Grant funded by the Korean Government (NRF-2017S1A6A3A02079749). This article is a revised and modified version of the master dissertation by first author.

\section{References}

[1] F. M. Belz and K. Peattie, "Sustainability Marketing: A global perspective, (2nd Ed.)," John Wiley and Sons, (2012)

[2] A. Joshi, "Vedantic applications of augmented reality for strategic social marketing campaigns in India," Journal of Indian Business Research, vol.10, no.3, pp.256-273, (2018) DOI: 10.1108/JIBR-10-2017-0189 
[3] K. H. Kim, "Business planning model for behavioral changes, behavioral economics and social marketing," Overseas Trends and KOICA Health Project Analysis, KOICA, (2017)

[4] N. R. Lee and P. Kotler, "Social marketing: influencing behaviors for good," Sage Publications, (2011)

[5] R. C. Lefebvre, "Social marketing and social change: strategies and tools for improving health, well-being and the environment," San Francisco: Jossey-Bass, (2013)

[6] H. J. Paek, "Social marketing," Communication Books, (2013)

[7] D. S. Mutum, E. Ghazali, and A. Kumar, "Social marketing: India, Pakistan and Bangladesh," in Nguyen, B. and Rowley, C. (Eds.), Ethical and Social Marketing in Asia: Incorporating Fairness Management, (2015)

[8] P. G. Wasan and G. Tripathi, "Revisiting social marketing mix: a socio-cultural perspective," Journal of Services Research, vol.14. no.2, pp.127-136, (2014)

[9] G. O'Sullivan, "The saathiya trusted parter program in India: meeting young couples; reproductive health needs," Social Marketing Quarterly, vol.14, no.3, pp.109-120, (2008) DOI: 10.1080/15245000802261324

[10] N. Samad, S. Nwankwo, and A. Gbadamosi, "Branding in contraceptive social marketing: the Pakistani experience," Social Marketing Quarterly, vol.16, no.2, pp.50-68, (2010) DOI: 10.1080/15245001003746758

[11] S. Sharma and A. Rehman, "Social media marketing: a study of select sectors in India," The International Journal of Management, vol.5, no.4, pp.1-9, (2016)

[12] A. Singh, G. K. Saini, and S. Majumdar, "Application of social marketing in social entrepreneurship: evidence from India,” Social Marketing Quarterly, vol.21, no.3, pp.152-172, (2015) DOI:10.1177/1524500415595208

[13] Ministry of Corporate Affairs (Government of India), The Companies Act 2013, https://www.mca.gov.in/Ministry/pdf/CompaniesAct2013.pdf, Oct 10, (2019)

[14] Population Services International, https://www.psi.org, Sep 01, (2019) 
Analyzing Social Marketing Characteristics of Indian Companies

This page is empty by intention. 